\title{
E・ZアクセスおよびE・Zリンクを用いた腹腔鏡下子宮筋腫核出術の工夫
}

秋田大学大学院医学系研究科医学専攻機能展開医学系産婦人科学講座 熊澤由紀代、白澤弘光、佐藤 亘、熊谷 仁、寺田幸弘

\section{Laparoscopic myomectomy using the EZ-access and EZ-link for reduced port surgery}

\author{
Yukiyo Kumazawa, Hiromitu Sirasawa, Wataru Sato, Jin Kumagai, Yukihiro Terada \\ Department of Obstetrics and Gynecology, Akita University Graduate School of Medicine
}

\begin{abstract}
:
Background: A 12-mm port is needed for the insertion of a thread for uterine myometrium sutures and laparoscopic power morcellation. Reduced port surgery and needlescopic surgery are becoming standard procedures for which a 12 $\mathrm{mm}$ port is not appropriate. The Food and Drug Administration has limited the use of morcellation, hence another method for extraction of uterine myomas is needed.

Method: The EZ-access was placed at the umbilicus with the EZ-link combined with the EZ-sheath. The thread could be inserted through the EZ-link, and myoma extraction was less complicated using a cold knife through the EZ-access.

Result: Insertion of 9-13-mm-diameter forceps is possible through the EZ-link and EZ-access used as a 12-mm port. To prevent air leak through the EZ-link when 5-mm devices are used, the EZ-link was inserted inside the EZ-sheath. Conclusion: The EZ-link combined with the EZ-sheath as a 12-mm port is beneficial from the cosmetic and economic viewpoints.
\end{abstract}

Key words: laparoscopic myomectomy, EZ-access, EZ-link, reduced port surgery

\section{緒言}

腹腔鏡下子宮筋腫核出術 (laparoscopic myomectomy: LM）は子宮筋層縫合のための針糸の 挿入や筋腫把持鉗子としての10ミリ鉪子の使用、 モルセレーターを使った筋腫の体外取り出しのた め、 $12 \mathrm{~mm}$ ポートの挿入が必要である。しかし近 年、低侵襲・整容性が重視され、単孔式手術やポ 一トの減数化である reduced port surgery (RPS)、ポートの細径化であるNeedlescopic surgery（NS）が普及してきており、術創をより 小さくし疼痛を軽減させることは患者にとって有 益である。またFDAの勧告によりモルセレータ 一が一部販売中止となったため、筋腫の取り出し 方法については工夫が必要である。当院では、 2011年よりRPSを導入し、ラッププロテクターTM $/ \mathrm{E} \cdot \mathrm{Z}$ ア セス ${ }^{\mathrm{TM}}$ (八光メディカル) の使用を
開始した。当院においてLMは、 $5 \mathrm{~mm}$ トロカー 3 本 (内 1 本はカメラポート) と $12 \mathrm{~mm}$ トロカー 1 本の 4 ポート法で施行していたが、臍部にラッ ププロテクター ${ }^{\mathrm{TM}} / \mathrm{E} \cdot \mathrm{Z} ア ク セ ス^{\mathrm{TM}}$ を装着し、 $12 \mathrm{~mm}$ ポートの代わりにE・Zリンク ${ }^{\mathrm{TM}}$ (八光メ

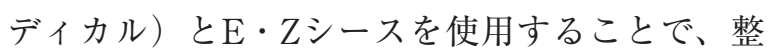
容性と操作性に優れたLMの方法を考案したので 報告する。

\section{手術手技}

全身麻酔下に、臍窩を縦に約 $2.5 \mathrm{~cm}$ 切開しラッ ププロテクターTM $/ \mathrm{E} ・ Z ア ク セ ス^{\mathrm{TM}}$ を装着する。 同部分に $5 \mathrm{~mm}$ のメラポートと $\mathrm{E} ・ Z$ カースを

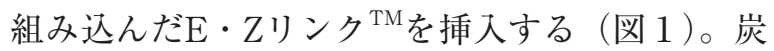
酸ガスで気腹を行い、両下腹部に $5 \mathrm{~mm}$ のトロカ 一を挿入（可能ならば $3.5 \mathrm{~mm}$ の細径鉗子）し 3 孔 式で行う。経胵的に子宮マニピュレーターTM (ア 


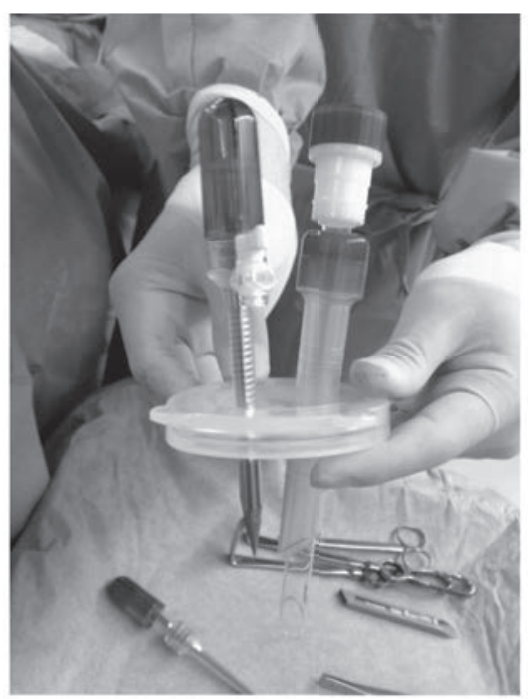

図 $1 \quad \mathrm{E} \cdot Z$ アアクセス ${ }^{\mathrm{TM}}$ へとポートの装着 $\mathrm{E} \cdot \mathrm{Z}$ アセス ${ }^{\mathrm{TM}}$ にスコープ挿入用の 5 $\mathrm{mm}$ ポートとE・Zシースを組み込んだ $\mathrm{E} \cdot \mathrm{Z}$ リンク ${ }^{\mathrm{TM}}$ を挿入

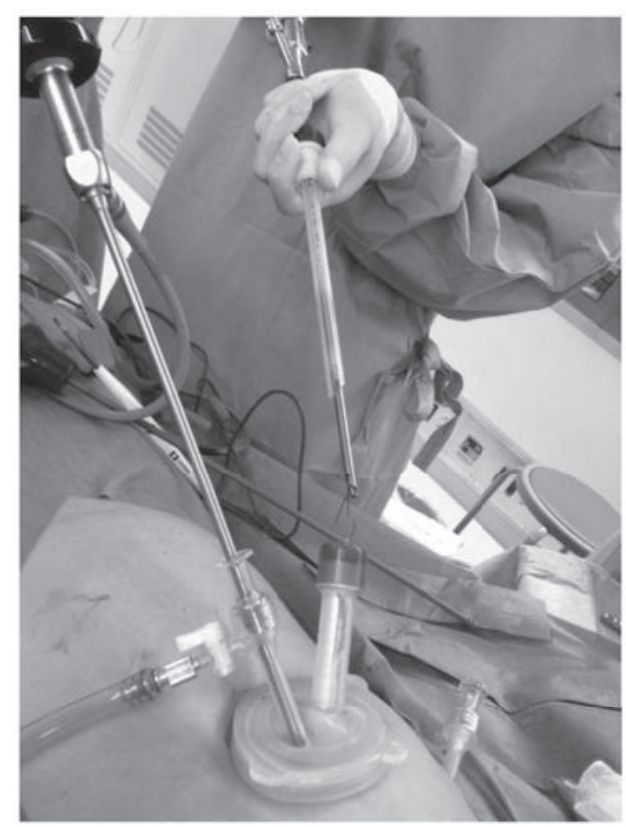

図2 E・Zリンク ${ }^{\mathrm{TM}}$ からの針系の挿入

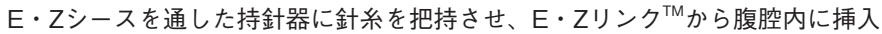

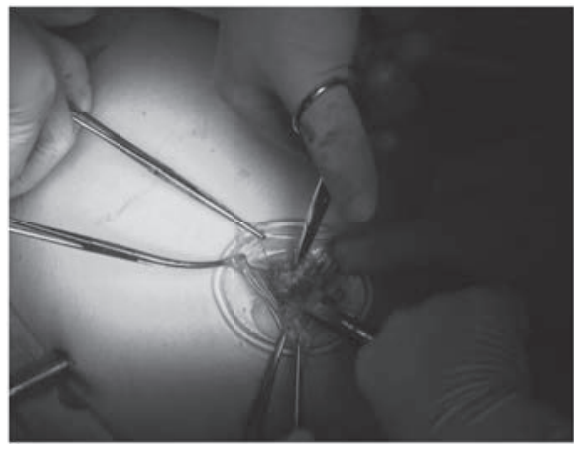

図3 子宮筋腫の細切(1)

ラッププロテクター ${ }^{\mathrm{TM}} / \mathrm{E} ・ Z$ マアセス ${ }^{\mathrm{T} \mathrm{M}}$ 外した臍部から直視下に回収袋内で筋腫を 細切して体外へ取り出す
トムメディカル）を装着する。子宮筋層縫合のた めの針糸の挿入・回収は $\mathrm{E} \cdot Z$ リンク ${ }^{\mathrm{TM}}$ から行う（図 $2)$ 。 E・Zシースを通した持針器に針系を把持さ せ、 $\mathrm{E} ・ \mathrm{Z} リ ン ク^{\mathrm{TM}}$ から腹腔内に挿入する。核出 した子宮筋腫は、速やかに回収袋に挿入し、ラッ ププロテクター ${ }^{\mathrm{TM}} / \mathrm{E} \cdot \mathrm{Z} ア ク セ ス^{\mathrm{TM}}$ を外した臍 部から直視下に袋内で細切して体外へ取り出す (図 3 )。細切する際には左右下腹部のいずれかの ポートからスコープを挿入し、腹腔内から回収袋 を観察し、腹壁および腹腔内臟器の巻き込みや損 傷がないことを確認しながら行う（図４）。

\section{考察}

RPS（Reduced Port Surgery）は、創をより 小さく少なくすることを重視した腹腔鏡下手術の 手法であり、特に 1 つの創よりスコープや鉗子を
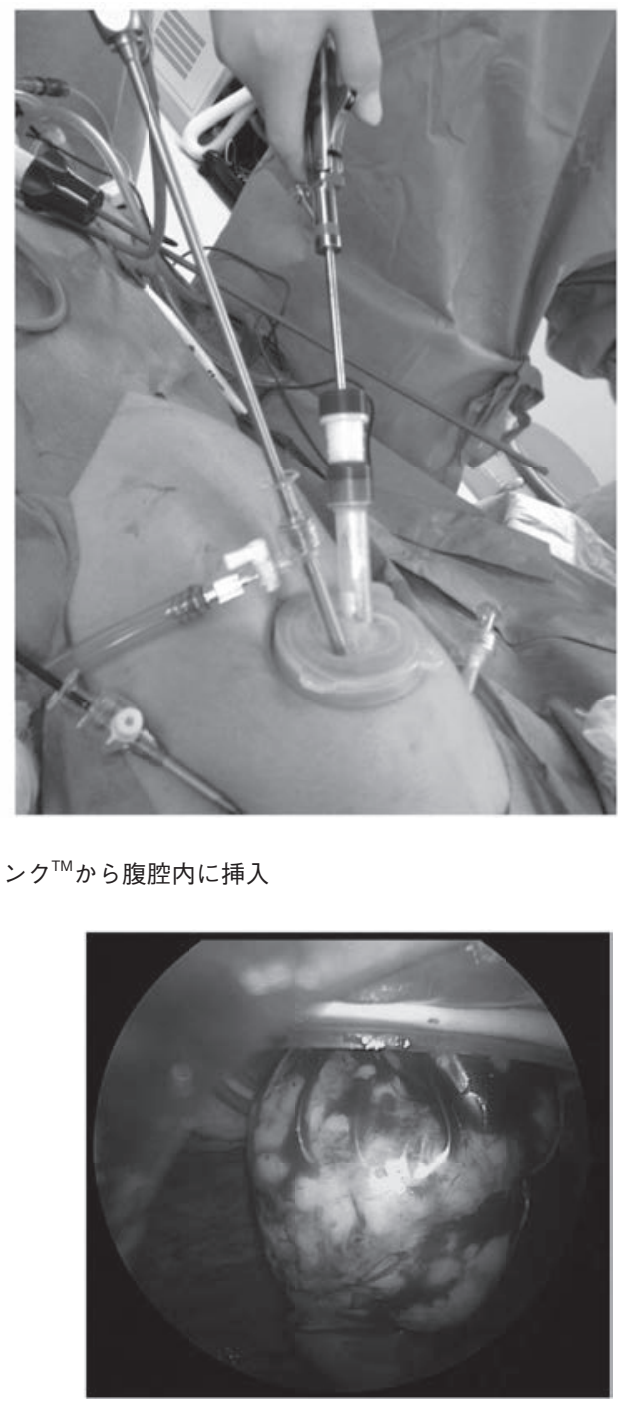

図4 子宮筋腫の細節(2)

下腹部のポートからスコープを挿入し 腹腔内から回収袋を観察し、袋の破損な いことを確認 
挿入して手術を行う単孔式腹腔鏡下手術は2009年 頃より婦人科領域に導入され普及している ${ }^{1)}$ 。単 孔式手術では多孔式手術と比べ、整容性のみなら ず術後の疼痛や回復に優れているが、針子操作や 術視野の展開には術者のより高度な技術を必要と する。単孔式手術にはmultiple trocar法とmultichannel port法があり、後者にはSILSポート ${ }^{\mathrm{TM}}$ （COVIDIEN）を使用するSILS法や手術用手袋を 使用するGlove法、E・Zアクセス法などがある。 それぞれの方法でポートの装着のしやすさや針子 の操作性、コス卜面の違いなどがあり、池内らに よればポートの設置時間はSILSポート法が最短 であり、操作鉗子間の距離はE・Zアクセス法で 最も長く、コストはE・Zアクセス法が最も安価 であったと報告している ${ }^{2)}$ 。当院では鉗子の操作 性が高く低コストであるE・Zアクセス法を2011 年より導入している。

$\mathrm{E} ・ \mathrm{Z}$ アクセス ${ }^{\mathrm{TM}}$ は、 $5 \mathrm{~mm}$ トロカー 3 本もし くは $12 \mathrm{~mm}$ トロカー 1 本と $5 \mathrm{~mm}$ トロカー 2 本の最 大 3 本のポートが装着可能である。子宮筋腫核出 術時には針糸の挿入や 10 ミリのクロー鉗子・ミオ ームボーラーなどの鉬子を挿入するために、 $12 \mathrm{~mm}$ ポートの挿入が必要となる場合が多い。 $12 \mathrm{~mm}$ ポートにはXCEL ${ }^{\mathrm{TM}} 12 \mathrm{~mm}$ (ETHICON) や オプティカルトロカー ${ }^{\mathrm{TM}} 12 \mathrm{~mm}$ (COVIDIEN) な どが多施設で広く使用されているが、単孔式でこ れらのトロカーを用いる場合、鉗子間の距離が短 くなり可動性が狭まれるうえに、ヘッドが大きい ためへッド同士の干渉も加わり操作性がさらに低

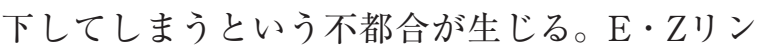
$ク^{\mathrm{TM}}$ は2013年 6 月15日に発売された、 $\mathrm{E} ・ \mathrm{Z} ア ク$ セス ${ }^{\mathrm{TM}}$ に $10 / 12 \mathrm{~mm}$ ポートを追加するために使用 する製品である（図 5 )。特徴として他の $12 \mathrm{~mm}$ ポートと比べてへッドがかなり小さく、単孔式手 術で使用するのに適したシンプルなデザインとなっ ている（図6）。問題点としては、 $10 \mathrm{~mm} / 12 \mathrm{~mm}$ の 内視鏡用デバイスを挿入するために作られた製品 であるため、 $\mathrm{E} ・ Z$ 洸 ${ }^{\mathrm{TM}}$ から $5 \mathrm{~mm}$ 鉗子を使 用すると気腹漏れを起こしてしまうことである。 そこで、当院ではサンドバルーン用シースである $\mathrm{E} ・ Z$ Zース ${ }^{\mathrm{TM}} \mathrm{E} \cdot \mathrm{Z} リ ン ク^{\mathrm{TM}}$ より挿入した状態 で $5 \mathrm{~mm}$ 鉗子を使用するという工夫を行い、トロ カー間の干渉が少なくかつ気腹漏れなく $5 \mathrm{~mm}$ 鉗 子を使用することが可能となった。針糸を挿入す る際は、あらかじめE・Zシース 器に針を持たせ、 $\mathrm{E} ・ Z$ リリク ${ }^{\mathrm{TM}}$ から挿入するこ とで、手間なく安全に針の扦入が可能である。ま

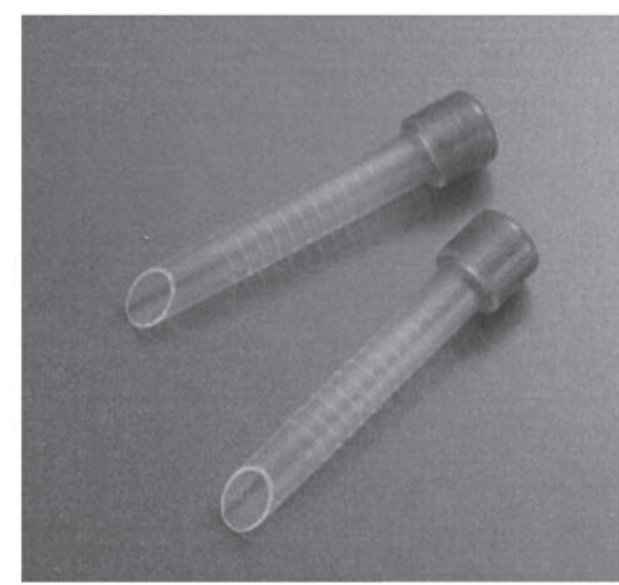

図5 E・Zリンク ${ }^{\mathrm{TM}}$

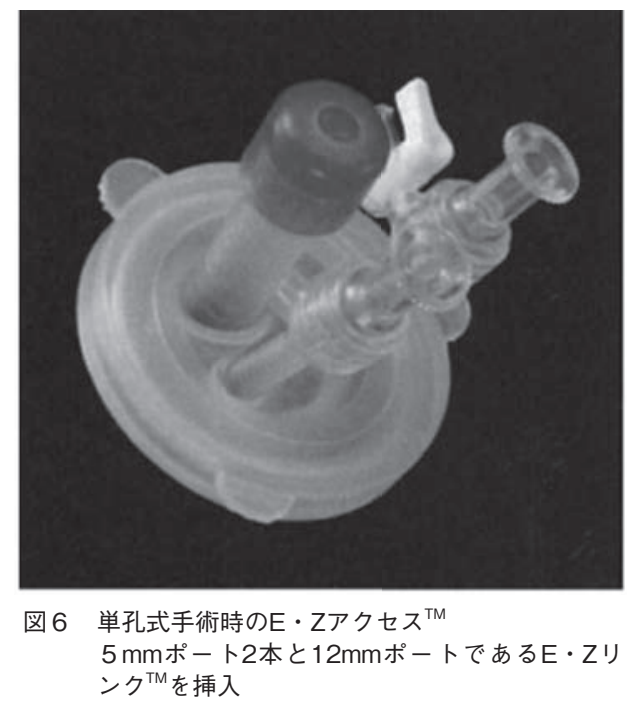

た針を体外へ取り出す際は、針を把持した持針器

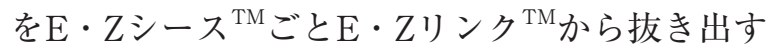
ことで、スムーズに回収することが出来る。針糸 の挿入に関して、針を把持させ体内に挿入する操 作にかかる時間は 10 秒未満であり、従来の $12 \mathrm{~mm}$ ポートからの挿入と比べて大差はなく、手術時間 の延長になるものではないと考えられる。今回 我々はLM時の縫合にこの方法を用いて行うこと で、 $12 \mathrm{~mm}$ の術創なく、RPSの概念に基づきなが ら、安全に針系を搬入・回収し手術を行うことが できた。

2014年 4 月、FDA（Food and Drug Administration；アメリカ食品医薬品局）の勧告によりエ チコン製モルセレーターの販売が中止となりその 使用が制限されたため、筋腫の体外への回収方法 については工夫が必要となった。ダグラス窩を切 開し腟式に回収する方法や、トロカー挿入部位を $1 \sim 2 \mathrm{~cm}$ 延長した創や $\mathrm{E} \cdot \mathrm{Z}$ アクセス装着部位な どから筋腫をメスにて索状に破切して体外へ取り 
出す方法などが報告されている る際には、癌組織があった場合には播種させる危 険性やParasitic myomasのリスクがあるため、核 出した筋腫は速やかに回収袋などに入れ飛散させ ないよう袋内で細切することが望ましい(5)。筋腫 の経腟的な回収は腟腔がある程度広く伸びがよい 症例では適しているが、腟腔が狭い未経産婦や高 度肥満症例では細切操作に難渋し、胵壁裂傷など を引き起こすリスクも高まる。我々は、 $\mathrm{E} ・ \mathrm{Z} ア$ クセス ${ }^{\mathrm{TM}}$ 装着部位を利用して筋腫を回収してお り、臍窩を利用した術創は術後の整容性に優れて おり、袋内で細切する操作もカメラで監視しなが ら安全に行うことができると考えている7)。また、 モルセレーターを使用した場合と比較すると、か なり医療材料費的に低コストである8

\section{結語}

腹胿鏡下子宮筋腫核出時にE・Zアクセス法にE・ Zリンク ${ }^{\mathrm{TM}}$ を使用することで、整容性を保ちなが ら子宮筋層縫合や筋腫の取り出しが可能であっ た。また、 $12 \mathrm{~mm}$ ポートである $\mathrm{E} ・ Z$ Zリンク ${ }^{\mathrm{TM}} に \mathrm{E} ・$ Zシースを扱入して使用する方法は、ヘットがス マートで干渉が少ないため操作性に優れており、 単孔式手術の際にLM以外の術式でも使用できる 有用な方法であると考えられる。

\section{文献}

1 ）平野浩紀、他：当院産婦人科におけるSingle Incision Laparoscopic Surgery（SILS）、現代産婦人科、2009； $58: 215-220$

2 ) 池内理江、他：当科における単孔式腹腔鏡下手術の 現状-SILS、SSL、EZアクセスについてー、日産婦 内視鏡学会、2012；28（2）：667-672

3 ) Fabio Montella, et al: A safe method of vaginal longitudional morcellation of bulky uterus with endometrial cancer in a bag at lararoscopy, Surg Endosc、2014: $28: 1949-1953$

4 ）竹内裕之、他：腹腔鏡下子宮筋腫核出術の試み、日 産婦内視鏡学会、1997；13（1）：97-101

5 ) Cohen SL, et al: Contained power morcellation within an insufflated isolation bag, Obste Gynecol: 2014; 124 (3) : 491-497

6 ）平野浩紀、他：EZアクセスを利用した単孔式腹腔鏡 下筋腫核出術での安全かつ迅速な筋腫核体外取り出 し方法、日産婦内視鏡学会、2011；27（2）：446-449

7 ) Cuesta MA, et al: The "invisible cholecystectomy": a transumblical laparoscopic operation without a scar, Surg Endosc, $2008 ; 22: 1211-1213$

8 ) 坂本愛子、他： 2 孔式腹腔鏡下筋腫核出術における
EZアクセス ${ }^{\mathrm{TM}}$ の有用性、日産婦内視鏡学会、2012; 28 (1) : 453-458 